\title{
From the discovery of the Malta fever's agent to the discovery of a marine mammal reservoir, brucellosis has continuously been a re-emerging zoonosis
}

\author{
Jacques GODFROID $^{\mathrm{a}, \mathrm{b} *}$, Axel ClOECKAERT ${ }^{\mathrm{c}}$, Jean-Pierre LIAUTARD ${ }^{\mathrm{d}}$, \\ Stephan KoHLER ${ }^{\mathrm{d}}$, David FreTIN ${ }^{\mathrm{a}}$, Karl WALRAVENS ${ }^{\mathrm{a}}$, \\ Bruno GARIN-BASTUJI ${ }^{\mathrm{e}}$, Jean-Jacques LETESSON ${ }^{\mathrm{f}}$
}

${ }^{a}$ Département de Bactériologie et d'Immunologie, Centre d'Étude et de Recherches Vétérinaires et Agrochimiques, 99 Groeselenberg, 1180 Uccle, Belgium

b Present address: University of Pretoria, Faculty of Veterinary Science, Private Bag X04, Onderstepoort 0110, South Africa

${ }^{c}$ Unité BioAgresseurs, Santé, Environnement, Institut National de la Recherche Agronomique, 37380 Nouzilly, France

d INSERM U-431, Université Montpellier, 2 Place E. Bataillon, 34095 Montpellier, France e Centre National de Référence des Brucella, Laboratoire National et OIE/FAO de Référence pour la Brucellose Animale - Unité Zoonoses Bactériennes, Agence Française de Sécurité Sanitaire des Aliments (AFSSA), 23 Avenue du Général-de-Gaulle, 94706 Maisons-Alfort Cedex, France

${ }^{\mathrm{f}}$ Laboratoire d'Immunologie et de Microbiologie, Unité de Recherche en Biologie Moléculaire (URBM), Département de biologie, Facultés Universitaires Notre-Dame de la Paix, Rue de Bruxelles 61, 5000 Namur, Belgium

(Received 3 May 2004; accepted 16 September 2004)

\begin{abstract}
Brucellosis is not a sustainable disease in humans. The source of human infection always resides in domestic or wild animal reservoirs. The routes of infection are multiple: foodborne, occupational or recreational, linked to travel and even to bioterrorism. New Brucella strains or species may emerge and existing Brucella species adapt to changing social, cultural, travel and agricultural environment. Brucella melitensis is the most important zoonotic agent, followed by Brucella abortus and Brucella suis. This correlates with the fact that worldwide, the control of bovine brucellosis (due to $B$. abortus) has been achieved to a greater extent than the control of sheep and goat brucellosis (due to B. melitensis), these latter species being the most important domestic animals in many developing countries. The long duration and high cost of treatment of human brucellosis reduces the efficacy of the therapy. There is no human vaccine for brucellosis and the occurrence of brucellosis is directly linked to the status of animal brucellosis in a region. In this context, the Word Health Organization has defined the development of a human vaccine, besides the implementation of control and eradication programs in animals, as a high priority. The pathogenicity for humans of $B$. suis biovars 1,3 and 4 is well established, whereas $B$. suis biovar 2 seems to be less pathogenic. Indeed, although hunters and pig farmers have repeatably experienced infectious contact with $B$. suis biovar 2 (found in wild boar and outdoor-rearing pigs in Europe), isolation of $B$. suis biovar 2 from human samples have only been seldom reported. Marine mammal brucellosis, due to two new proposed Brucella species i.e. B. cetaceae and B. pinnipediae, represents a new zoonotic threat but the pathogenicity for humans of the different Brucella species found in cetaceans and pinnipeds still has to be clearly established.
\end{abstract}

Brucella / animal and human brucellosis / zoonoses / domestic and wildlife reservoir

\footnotetext{
* Corresponding author: jacques.godfroid@up.ac.za
} 


\section{Table of contents}

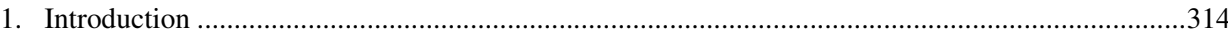

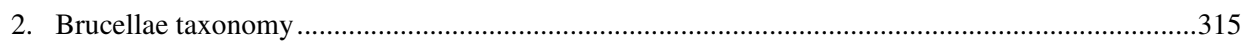

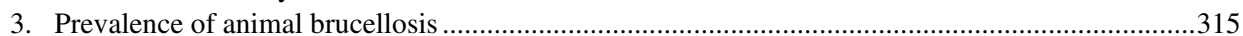

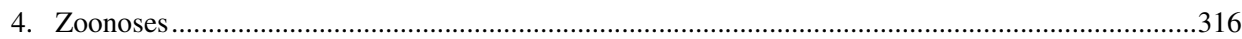

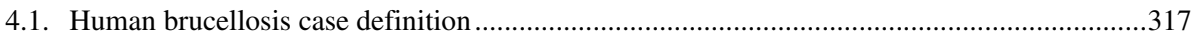

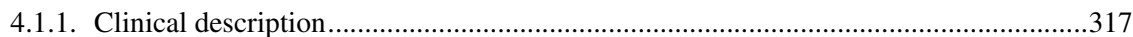

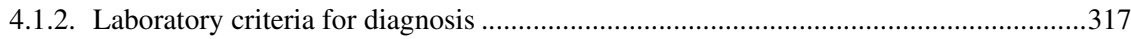

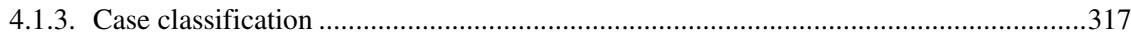

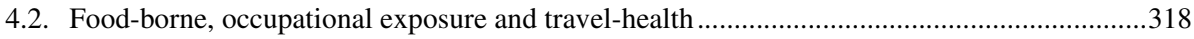

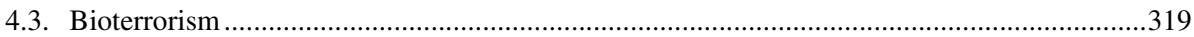

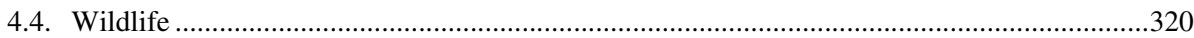

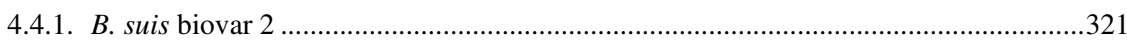

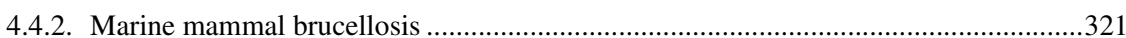

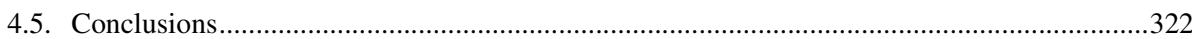

\section{INTRODUCTION}

We know from written resources that sheep and goats were the primary domestic animals in the Roman Empire. Small ruminants milk was used to make cheese, one of the primary ingredients in Roman cuisine. It was therefore hypothesized that milk and milk products were important sources of an infectious food-borne disease that was later know as the "Maltese fever" (i.e. brucellosis due to Brucella melitensis). The Roman town of Herculaneum was destroyed by the tremendous volcanic eruption of Mount Vesuvius in August 79 A.D. Recently, L. Capasso found bone lesions typical of brucellosis in adult skeletal remains of people killed during the first volcanic surge of Mount Vesuvius [16]. He also demonstrated by scanning electron microscopy analysis of a buried carbonized cheese, the presence of cocco-like forms that were morphologically consistent with Brucella spp. [16]. Sir David Bruce isolated in 1887 the organism (Micrococcus melitensis) responsible for Maltese fever from a British soldier who died from the disease in Malta [15]. This bacterium was renamed Brucella melitensis in his honor. In 1905, Zammit demonstrated, again in Malta, the zoonotic nature of $B$. melitensis by isolating it from goat's milk [78].

In April 2003, the first report of community-acquired human infections with marine mammal-associated Brucella spp. was published. The authors described the identification of these strains in two patients with neurobrucellosis and intracerebral granulomas [66].

These facts highlight that Brucella spp. has always been of zoonotic concern through out History. Human brucellosis has always been associated with an animal (domestic or wild) reservoir of Brucella spp. However, the main sources of infection(s) as well as the routes of contamination may differ. Because each Brucella species (or even biovar) has distinctive epidemiologic features, the complexity of the interaction between Brucella spp., animals and humans has increased. Moreover, new Brucella strains or species may emerge and existing $\mathrm{Bru}$ cella spp. adapt to changing social, cultural, travel and agricultural environments. Hence, the global human and animal brucellosis picture will, in essence, always remain incomplete.

The aim of this paper is (1) to review the known sources and routes of Brucella spp. infections for humans and (2) to assess the new potential zoonotic threat of Brucella spp. found in wildlife reservoirs, with particular emphasis on Brucella suis biovar 2 infection in the wild boar (Sus scrofa) in Europe and marine mammal Brucella spp. infections that seem to be present in all the 
oceans covering our planet. Animal diagnostic procedures, vaccination protocols, control and eradication programs, human brucellosis diagnosis and medical or surgical management as well as recent advances in the understanding of the biology, virulence and evolution of the genus Brucella, through genomic and post-genomic techniques, will not be covered per se and the reader is directed to recent reviews and reference books on all these aspects $[3,6-9,13,30,55,58$, 71, 76, 77].

\section{BRUCELLAE TAXONOMY}

Brucellae are Gram-negative, facultative intracellular bacteria that can infect many species of animals and man. Six species are recognized within the genus Brucella: Brucella abortus, Brucella melitensis, Brucella suis, Brucella ovis, Brucella canis, and Brucella neotomae [3, 27]. This classification is mainly based on the difference in host preference and in pathogenicity. Distinction between species and biovars is currently performed by differential laboratory tests $[3,27]$. Although it has been proposed that the Brucella species should be grouped as biovars of a single species based on DNADNA hybridization studies [71] and on the comparison of the genome of $B$. melitensis [30] and B. suis [58], the current classification of brucellae in species according to differences in host preference and in pathogenicity should be preferred $[23,53]$.

Worldwide, the main pathogenic species for domestic animals are B. abortus, responsible for bovine brucellosis; B. melitensis, the main etiologic agent of small ruminant brucellosis; and B. suis responsible for swine brucellosis. These three Brucella species may cause abortion in their hosts and because of the presence of brucellosis in a herd (or flock), a region or a country, international veterinary regulations impose restrictions on animal movements and trade, which result in huge economic losses [7, 8, 28]. $B$. ovis and B. canis are responsible for ram epididymitis and canine brucellosis respec- tively. For B. neotomae only strains isolated from desert rats have been reported. Albeit their respective host preferences, different Brucella strains have also been isolated from a great variety of wildlife species such as bison (Bison bison), elk (Cervus elaphus), feral swine and wild boar (Sus scrofa), fox (Vulpes vulpes), hare (Lepus capensis), African buffalo (Syncerus caffer), reindeer (Rangifer tarandus tarandus), caribou (Rangifer tarandus groenlandicus), chamois (Rupicapra rubicapra) and ibex (Capra ibex) and wildlife has to be considered as a reservoir for zoonotic brucellosis [29, 39, 60]. The broad spectrum of Brucella isolates has recently been enlarged to marine mammals. A number of recent reports describe the isolation and characterization of $\mathrm{Bru}$ cella strains from a wide variety of marine mammals $[22,32,36]$. These strains have been identified as brucellae, however their overall characteristics are not assimilable to those of any of the six recognized Brucella species [22, 23, 45].

\section{PREVALENCE OF ANIMAL BRUCELLOSIS}

Information about animal brucellosis (world wide) is available on the Office International des Epizooties (OIE) website (http://www.oie.int), by using the HandiStatus tool (i.e. Help with World Animal Disease Status, version 2) containing information on animal diseases (like brucellosis) that have serious consequences for international trade or public health. This information is regularly updated based on emergency, monthly and annual reports sent to the Central Bureau of the OIE by the veterinary administrations of countries and other official sources. Globally, despite the remarkable results achieved by the majority of industrialized countries, where bovine brucellosis has been eradicated or controlled, small ruminant brucellosis remains a problem in some of these countries as well as in all developing countries [50]. Basically, in developing countries, brucellosis is almost 
always present where small ruminants are kept. B. melitensis in cattle has emerged as an increasingly serious public health problem in some southern European countries and Israel as a result of the consumption of unpasteurized milk since $B$. melitensis is capable of colonizing the bovine udder [11, 72]. A related problem has been noted in Mexico and some South American countries, where $B$. suis biovar 1 has become established in cattle [12, 47, 64]. Moreover, in some areas of these countries, cattle are now believed to be more important than pigs as a source of $B$. suis biovar 1 infection for humans, because $B$. suis biovar 1 is capable of colonizing the bovine udder as B. melitensis does [26]. B. melitensis infections occur in cattle almost exclusively when these infections are present in small ruminants [72]. It is therefore likely that B. melitensis infections in cattle are not sustainable infections. In this case, the implementation of control measures in the primary host (i.e. small ruminants), without any additional specific measures in cattle (like vaccination, for example) is likely to solve the problem by exhausting the source of infection for cattle [40]. Although it is claimed that $B$. suis biovar 1 has become established in cattle [26], it still remains to be proven that it may do so without a continuous influx of new bacteria from the pig reservoir.

Areas currently considered to have high brucellosis prevalence areas are the Middle East, the Mediterranean Basin (Portugal, Spain, Italy, Greece, Turkey, Near East, North Africa), South and Central America, SouthEastern Europe, Asia, Africa, and the Caribbean. In some regions, camel brucellosis due to B. melitensis or B. abortus infections is another important source of human infections $[1,2,10,25,59]$. As a consequence, the importance of zoonotic brucellosis reservoirs is such that the World Health Organization (WHO) stated: "We regard brucellosis as the world's most widespread of all zoonoses and apart from its toll on people, it has an enormous impact on the animal industry". As the international trade in ani- mals and animal products and movement of people increase, the risk of introduction and re-introduction of brucellosis is growing.

\section{ZOONOSES}

Brucellosis is an established zoonosis, infection having been attributed to at least four of the six recognized Brucella species in terrestrial mammals, $B$. ovis and $B$. neotomae being the exceptions. B. melitensis is by far, the most important zoonotic agent, but $B$. abortus and $B$. suis also constitute a significant threat [6]. B. ovis has not been demonstrated to cause overt disease in humans, although it is widespread in sheep. $B$. canis can cause disease in humans, although this is rare even in countries where the infection is common in dogs [17]. Recently, human brucellosis has also been attributed to some marine mammal strains $[14,66]$. Human-to-human transmission by tissue transplantation or sexual contact have occasionally been reported but are, in epidemiological terms, insignificant [48].

Control and eradication of brucellosis in domestic animals have important public health implications. Test-and-slaughter programs, in conjunction with vaccination and, in a later stage, whole herd depopulation, are the major methods of control and eventually eradication of animal brucellosis [6$8,26,28]$. As a general rule, prevention of human brucellosis depends predominantly on the control of the disease in animals [6, $7,68]$. For example, the rise of human brucellosis cases reported in Greece in 1995 is assumed to be due to the discontinuation of the small ruminant vaccination program against brucellosis that was followed by an increase in the prevalence of the disease in small ruminants [52]. Once an emergency mass-vaccination program of young and adult animals was reinforced, the number of human cases again decreased [52]. Specific regulations have been implemented in the European Union (EU) concerning measures for protection against specified zoonoses and specified zoonotic agents in animals and products of animal origin in order 
to prevent outbreaks of food-borne infections and intoxications (Council Directive 92/117/EEC of 17 December 1992).

\subsection{Human brucellosis case definition}

The following case definitions are taken from the US Center of Disease Control (CDC) [18].

\subsubsection{Clinical description}

An illness characterized by acute or insidious onset of fever, night sweats, undue fatigue, anorexia, weight loss, headache, and arthralgia.

\subsubsection{Laboratory criteria for diagnosis}

- Isolation of Brucella spp. from a clinical specimen, or

- Fourfold or greater rise in Brucella agglutination titer between acute- and convalescent-phase serum specimens obtained greater than or equal to two weeks apart and studied at the same laboratory, or

- Demonstration by immunofluorescence of Brucella spp. in a clinical specimen.

\subsubsection{Case classification}

- Probable: a clinically compatible case that is epidemiologically linked to a confirmed case or that has supportive serology (i.e. Brucella agglutination titer of greater than or equal to 160 in one or more serum specimens obtained after the onset of symptoms).

- Confirmed: a clinically compatible case that is laboratory confirmed.

In countries where brucellosis is enzootic (i.e. present in animal reservoirs), human confirmed cases are based on clinical symptoms associated with positive serology without attempts to isolate Brucella spp., in the vast majority of suspected or confirmed cases. In countries where animal brucellosis has virtually been eradicated, for every single suspected case of human brucellosis, particularly in the presence of positive serology, the emphasis is put on the epidemiological inquiry in order to confirm the case. This inquiry has to trace back the potential source of contamination. The importance of the epidemiological investigation can be exemplified by the situation in Belgium. In this country which has been free of brucellosis in cattle since 2000 and in sheep, goats and domestic pigs for decades (and thus where no domestic animal reservoir exists), more than a hundred positive human brucellosis serology cases are registered every year in the national reference centre for animal and human brucellosis. Beforehand, we know that the number of false positive serological reactions will increase with the decrease of the actual prevalence of the disease. Therefore, in a country virtually free of animal brucellosis, confirmation by isolation of Brucella spp. from a clinical specimen is required. In Belgium, for the 1993-2003 period, from zero to seven human cases/year were confirmed by the isolation of Brucella spp. in clinical specimens. For all these confirmed cases, an epidemiological link was clearly identified. Indeed, besides one occupational case of B. abortus infection (in the nineties some foci of infections remained in the Belgian cattle population) and one occupational case of B. suis infection (this latter case occurred in a butcher preparing imported feral pig meat [41]), all other human brucellosis cases were food-borne infections due to B. melitensis and were "imported" cases, from Mediterranean countries. Thus, in countries virtually free of animal brucellosis and in the absence of an established epidemiological link, human brucellosis can virtually be ruled out and positive serological results have to be classified as false positive serological results [43]. False positive serological reactions in animal brucellosis are well documented in EU Member States virtually free of animal brucellosis and they represent currently one of the most important problems the veterinary authorities have to deal with [42]. 


\subsection{Food-borne, occupational exposure and travel-health}

Worldwide, the true incidence of human brucellosis is unknown. Reported incidence in endemic-disease areas varies widely, from $<0.01$ to $>200$ per 100000 population [26]. For example, Egypt, the Islamic Republic of Iran, Jordan, Oman, Saudi Arabia and Syrian Arab Republic reported a combined annual total of more than 90000 cases of human brucellosis in 1990 [10]. The low incidence reported in known brucellosis-endemic areas may reflect the absence or the low levels of surveillance and reporting [26, 50, 68]. In 2000, altogether 2857 human cases (in 14 Member States) were reported in the EU compared to 3899 cases (in 13 Member States) in 1999 [40]. As in previous years, only very few human cases occurred in those Member States that had acquired the "Officially Brucellosis Free" status in cattle and small ruminants [40].

Human brucellosis is not considered a contagious disease $[6,21,35]$. Therefore, clustering could result from common-source outbreaks or time-space clustering of factors that increase the risk of infection [21, 35]. In California, human brucellosis evolved between 1973 and 1992 from an occupational (slaughterhouse cases) to a foodborne illness with a higher incidence in Hispanics, especially in children and teenagers, compared with non-Hispanic whites and African Americans [21]. Therefore, public health programs in California should focus on educating Hispanic populations about the risk of consuming dairy products, such as soft cheeses, made from unpasteurized milk [35]. The importance of screening household members of acute brucellosis cases in endemic areas, like Saudi Arabia, has recently been emphasized: screening family members of an index case of acute brucellosis detected additional cases [4]. Humans are often the first to be reported as infected in an area into which the disease has recently been introduced and epidemic human infections by $B$. melitensis have developed among people frequently in contact with infected goat herds or goat manure, as recently reported in Argentina [73].

Consumption of contaminated foods and occupational contact are the major risks of infection. Consumption of unpasteurized cow, small ruminants or camel milk and milk products (cheese and sour milk, for example) is considered to be the main route of infection [4]. Meat of animals with brucellosis may also be a source of infection if eaten when insufficiently cooked. Some particular food habits, such as eating aborted foetuses as seen in Ecuador, may be responsible for human brucellosis.

Crushing the umbilical cord of newborn lambs and kids with the teeth is another risky habit. Skinning stillborn lambs and kids and aborted foetuses, which may be heavily contaminated with Brucella spp., also presents a high risk of brucellosis [10].

Infection may also result from the entry of the bacteria from diseased animals through skin lesions or mucous membranes or from inhalation of contaminated dust or aerosols. Inhalation is often responsible for a significant percentage of cases in abattoir employees [62]. Contamination of skin wounds may be a problem for persons working in slaughterhouses or meat packing plants or for veterinarians. Hunters may be infected through skin wounds or by accidentally ingesting the bacteria after cleaning deer, elk, moose, or wild pigs that they have killed. It is worthy to re-emphasize that in the USA and Australia, human brucellosis caused by B. suis biovars 1 or 3 is considered to be almost entirely occupational $[62,74]$, whereas in the Americas, brucellosis in humans caused by $B$. suis biovar 1 is emerging as an increasingly serious public health problem as a result of the consumption of unpasteurized cow milk since B. suis biovar 1 is capable of colonizing the bovine udder [26].

Brucellosis vaccines for animal use (B. abortus $\mathrm{B} 19$ and RB51, for cattle; B. melitensis Rev. 1 for small ruminants) are live attenuated vaccines. These vaccines 
show a residual virulence for humans and are known to cause disease in humans $[6,7$, 11, 19]. Adverse effects of strain persistence and secretion in milk have been encountered with the $B$. melitensis vaccine strain Rev. 1 [11]. Moreover, in Israel, field isolates obtained from vaccinated animals and from a human were classified as Rev.1-like field isolates and it was demonstrated that they originated from the Rev. 1 vaccine strain [11]. In 1997, nine persons (a farmer, four veterinary clinicians, and four veterinary students) in Manhattan, Kansas, were infected when participating in an attempted vaginal delivery, a caesarean delivery, and a necropsy on a stillborn calf that died because of $\mathrm{Bru}$ cella abortus RB51 infection [19].

Laboratory-acquired infections are occasionally reported and the inhalation of infective aerosols produced accidentally by microbiological techniques is the most frequent source of infection. Hence, in the laboratory, handling Brucella spp. in biosafety level 3 cabinets should always take place [3, 49].

Although many travellers are willing to experience new and exotic food and food preparations, they need to be educated with regards to the modes of disease transmission, so that they can take care when eating abroad, especially food from street vendors or traditional shops. Otherwise, they may expose themselves to Brucella spp. infections. Brucella spp. persist for several days in milk (even when it turns sour) and is known to flourish in soft fresh small ruminant cheese [6, 51]. It may also persist for weeks in ice cream and months in butter. Therefore, these products always have to be made from pasteurized milk [51]. For those travellers who may have contact with live or dead animals, infection may be transmitted via direct contact or aerosol. It is also worthy remembering that Brucella spp. can survive in the soil as well as in tap water for several weeks [51].

Despite many studies on the medical management of brucellosis over the past two decades, no major changes in the known therapeutic modalities have taken place [9,
$76,77]$. The treatment recommended by the WHO for acute brucellosis in adults is rifampicin 600 to $900 \mathrm{mg}$ and doxycycline $200 \mathrm{mg}$ daily for a minimum of six weeks [6]. However, although the most appropriate antibiotic combination is not known, other reports suggest that the combination of doxycline and an aminoglycoside is probably best and the addition of rifampicin may be a reasonnable option $[9,55]$. There is no consensus with regards to the best therapeutic regimen for chronic brucellosis in adults, simple or complicated brucellosis in children under 7 years of age and surgical management is only indicated in special cases $[9,51,55,68,76,77]$. Moreover, the long duration and high cost of treatment of human brucellosis reduce the efficacy of the therapy $[68,76,77]$.

No human brucellosis vaccine exits and it has been suggested that the development of such a vaccine should be treated as a priority area under the WHO global program on vaccination and immunization [7].

\subsection{Bioterrorism}

Bioterrorism and its potential for mass destruction have been subjects of increasing international concern. Production costs of biological weapons are low, and aerosol dispersal equipment from commercial sources can be adapted for biological weapon dissemination. As far as brucellosis is concerned, inhalation of only a few organisms is sufficient to cause a significant likelihood of infection. In a theoretical model of a bioterrorist attack and in the absence of an intervention program for 100000 persons exposed, a B. melitensis cloud would result in 82500 cases of brucellosis requiring extended therapy, with 413 deaths [46]. The economic impact of such a brucellosis bioterrorist attack would cost $\$ 477.7$ million per 100000 persons exposed [46].

In 1999, in Massachusetts, USA, a suspected case of brucellosis in a woman in which the atypical clinical presentation and suspicious circumstances surrounding the 
case raised the possibility of a bioterrorist attack [20]. The patient showed clinical signs consistent with brucellosis and positive serological results in brucellosis tests. The patient died of a cause that was unrelated to brucellosis. However, this episode highlighted the difficulties linked to the implementation of an early bioterrorism warning system. Because agents high on the list of possible biological terrorism have a very low incidence of natural infection in the United States and other industrialized countries, the risk for a false-positive result is high. Therefore, diagnostic laboratory testing should be integrated with epidemiological investigation when assessing potential covert biological terrorism events to rule out false-positive laboratory findings. In addition, support systems should be established to facilitate early recognition of rare and unusual emerging infectious diseases [20]. In order to re-emphasize the importance of epidemiological investigations, it is worth mentioning that in France, human cases of food-borne Yersinia enterocolitica serogroup O:9 (YO9, a known cross-reactive bacterium in brucellosis serology) infections were reported in the 1990s. Patients had positive serological results for brucellosis but no history of contact with Brucella-infected animals. Gastrointestinal symptoms suggested yersiniosis [43].

\subsection{Wildlife}

Wildlife brucellosis is a political issue: the livestock, hunting and game farming industries, and those involved in wildlife conservation and welfare, have conflicting interests $[31,75]$. Moreover, wildlife brucellosis represents a potential zoonotic threat [60]. When addressing wildlife brucellosis, it is very important to distinguish between a spillover of infection contracted from domestic animals and a sustainable infection in order to implement right decisions [39]. In the USA, the only known focus of B. abortus infection left is in bison (50\% of the animals tested positive) and elk in the Greater Yellowstone Area [60]. These last foci of infections have a very strong impact on the cattle industry in the region. Indeed, spill over from wildlife to cattle is regularly reported around these natural parks [60]. In zoonotic terms, due to the behavior of bison and elk, there is more risk of disease transmission from bison to man than from elk to man. But this pattern is changing due to the introduction of artificial elk feed grounds. Elk are more concentrated and less likely to calve in seclusion. Infected elk may also abort during the time they are congregated in the feed grounds. Under these conditions, the risk of disease spread from elk to elk and from elk to man (through skin wounds or by accidentally ingesting the bacteria after cleaning elk) is increased [60]. It is also worthy to note that to date, there is no vaccine that has proven to be safe and to provide a significative degree of protection in elk and bison, as well as in other wildlife species [39, 54, 65].

All Brucella species may infect different wildlife species, but $B$. suis deserves particular attention because, although there is a general host restriction pattern among the different species of Brucella, within the $B$. suis species, the different biovars preferentially infect different animal host species. Indeed, B. suis biovar 1 and 3 infect suidae, B. suis biovar 2 infects suidae and hares, $B$. suis biovar 4 infects reindeer and caribou and $B$. suis biovar 5 has been isolated from rodents in the former USSR.

B. suis biovars 1 or 3 infections in feral pigs are regularly reported in the southeastern states of the USA and in Queensland, Australia [60, 62, 70, 79]. In the USA, an extension of the geographical range of $B$. suis has occurred these last decades by release of $B$. suis infected feral pigs [70]. Human brucellosis is re-emerging in Queensland because of the recreational and occupational exposure to feral pigs infected with B. suis [62]. Moreover, the number of humans at risk is increasing because of the expansion of an export industry based on feral pig meat $[38,41]$. For example, in $1994, B$. suis biovar 1 was isolated from a butcher manipulating imported feral pig meat in Belgium 
where the last $B$. suis biovar 1 infection had been reported in a pig farmer in 1983 [41]. Although few recent outbreaks of human disease caused by $B$. suis biovar 4 have been reported [34], foci of the infection persist in the Arctic regions of North America and Russia and constitute a potential hazard for the local population. Surprisingly, the isolation of $B$. suis biovar 2 in humans has only been exceptionally reported in the international literature [57, 67]. Furthermore, the characterization of $B$. suis biovar 2 is missing in some of these reports, raising questions on the accuracy of the typing method used [57, 67].

\subsubsection{B. suis biovar 2}

Recently, brucellosis in wild boar due to B. suis biovar 2 was described in Belgium [41] and seems to be widely distributed among wild boar throughout Europe. Frequent contact between wild boar and cattle have been reported and the risk of cattle being exposed to $B$. suis biovar 2 has been assessed under field [5] and experimental conditions [42]. B. suis biovar 2 does not persit in cattle (self-cure mechanism) [42]. Hares have also been suspected to be the source of contamination of a cow in Denmark, a country where there are no freeranging wild boar populations [5]. So, there is a huge reservoir of $B$. suis biovar 2 in wildlife within the EU and wild boar (and possibly hares) have been reported to be widely and sustainably infected. A significant characteristic of $B$. suis biovar 2 is that this particular biovar is not an important pathogen for humans in contrast to $B$. suis biovars 1,3 and 4 . This is certainly one of the main reasons why no specific control measures have been taken so far to control B. suis biovar 2 infections in wild boar. There is a huge wild boar hunting industry in Europe. According to the very high prevalence rate of $B$. suis biovar 2 infections, recreational and occupational exposures of people to $B$. suis biovar 2 must occur frequently [41]. Albeit this important infection pressure, there is, to date, no documented report of $B$. suis biovar 2 infection in hunters in Europe, although B. suis biovar 2 was recently isolated in an immunocompromized hunter in France (B. Garin-Bastuji et al., manuscript in preparation). Moreover, for the period 1993-2003, B. suis biovar 2 infections have been reported in more than forty out-door rearing pig farms in France [37]. Although a huge percentage of pigs were infected, farmers did not complain of any clinical symptom consistent with brucellosis and all attempts to isolate $B$. suis biovar 2 from human clinical samples failed, despite some of the farmers showing transient serological titers [37]. Our preliminary observations indicate that $B$. suis biovar 2 is attenuated in the THP-1 human macrophage cell line compared to the fully virulent $B$. suis biovar 1 , although replication is similar in the J774 mouse macrophage cell line for both biovars (J. Godfroid and S. Kohler, unpublished results). Now that the genome of B. suis biovar 1 is sequenced [58], it would be interesting to identify the genomic sequences that are absent or differentially expressed in the B. suis biovar 2 genome as compared to the B. suis biovar 1 genome in order to identify sequences that could possibly be implicated in the pathogenicity of Brucella spp. in human macrophages. Once identified, these sequences could be further studied in the context of the development of new attenuated vaccine-candidates.

\subsubsection{Marine mammal brucellosis}

Prior to the first reports in 1994 of the isolation of Brucella spp. from stranded harbor seals (Phoca vitulina), harbor porpoises (Phocoena phocoena) and common dolphins (Delphinus delphis) on the coast of Scotland [63], and from an aborted foetus of a captive bottlenose dolphin (Tursiops truncatus) in California [32], brucellosis was not only unrecognized, but was not even suspected in marine mammals. The recent isolation of marine mammal $\mathrm{Bru}$ cella strains extends the ecologic range of the genus and, potentially, its scope as a 
zoonosis [26]. Currently, two reports indicate that marine mammal Brucella strains have a zoonotic potential. In England, a laboratory worker got infected and developed clinical brucellosis while handling cultures of a Brucella isolate from a seal [14]. In April 2003, the first report of communityacquired human infections with marine mammal-associated Brucella spp. was published. The authors described the identification of these strains in two patients with neurobrucellosis and intracerebral granulomas [66]. Both patients were young men from Peru and the route of infection was not discovered. One possible route of infection was the consumption of infected marine mammalian products; another was that marine mammal Brucella strains have been carried by other animal species. Seroconversion and abortion in cattle experimentally infected with Brucella spp. isolated from the Pacific harbor seal (Phoca vitulina richardsi) has been reported [61].

In Norway, there is a long tradition of harp seal (Phoca groenlandica), hooded seal (Cystophora cristata) and minke whale (Balaenoptera acutorostrata) meat consumption. Individuals from all these species have been found to be infected with Brucella spp. However, brucellosis has not been reported in humans at risk in Norway (e.g. whale- and seal-hunters, veterinary meat inspectors, other meat handlers and consumers) [69]. Brucellosis was recently identified in two species of baleen whales in the western North Pacific [56]. Although these animals are hunted for human consumption in Japan, there is to date no report of foodborne brucellosis due to the consumption of raw meat of these animals.

It has been proposed, based on host preference and molecular classification methods, that brucellae isolated from such diverse marine mammal species such as seals and dolphins could actually comprise at least two new species, Brucella cetaceae (preferentially infecting cetaceans) and Brucella pinnipediae (preferentially infecting pinnipeds) [23]. The respective pathogenicity for humans of B. cetaceae and B. pinnipediae needs to be further studied and documented.

\subsection{Conclusions}

Brucellosis is not a sustainable disease in humans. The source of human infection always resides in domestic or wild animal reservoirs and the routes of infection are multiple: food-borne, occupational or recreational, linked to travel and even to bioterrorism. B. melitensis is the most important zoonotic agent, followed by $B$. abortus and $B$. suis. In regions where human brucellosis is endemic, there is a great need for high-level recognition that animal and human health are inextricably linked and that the veterinary and public health sectors share the common goal of protecting, promoting and improving the health and well being of human populations. To date, no human vaccine exists and the long duration and high cost of treatment of human brucellosis reduce the efficacy of the therapy. Therefore, the development of a human vaccine should be treated as a priority.

Due to the lack of vaccine and to the burden associated with the disease management in man, the actual challenge remains to eradicate animal brucellosis. Besides the implementation of sound proficient eradication, surveillance and vigilance programs, the changing nature of the disease due to the changing animal husbandry and farming systems also has to be taken into account.

There is a huge reservoir of $B$. suis biovar 2 in wildlife in Europe: hares and wild boars have been reported to be widely and sustainably infected and spill over to outdoor reared domestic pigs and cattle has occurred. B. suis biovar 2 is peculiar in many aspects. A significant characteristic is that this particular biovar is not an important pathogen for humans, in contrast to $B$. suis biovars 1,3 and 4 . In the USA, there is a B. abortus reservoir in bison and elk that causes a threat to bovine brucellosis eradication programs [60]. Thus, wildlife should always be carefully monitored in order to prevent the 
re-emergence of brucellosis from the wildlife reservoir [39, 60].

B. melitensis has regularly been isolated from cattle in contact with infected sheep and goats in Mediterannean countries and represent a major zoonotic threat $[8,72]$. This challenges the preferred animal host speciation of brucellae. Indeed, B. abortus abortions in sheep, goats and pigs have been seldom reported in the past and not further documented in recent decades. Although B. suis biovars 1 and 3 isolations from cattle have been reported in the Americas and Australia, $B$. suis biovars 1 and 3 abortions have never been documented in cattle [24, $33]$. B. suis biovar 2 is a self limited infection in cattle [42]. Although B. melitensis abortions in cattle have been reported [72], the knowledge in the pathobiology of B. melitensis in cattle is surprisingly very scarce. In this perspective, the most important issue is whether $B$. melitensis is a sustainable infection in cattle, i.e. able to maintain itself in cattle without spill over from a reservoir in sheep and goats.

In the context of bioterrorism, it is of crucial importance to be able to discriminate quickly between true brucellosis and other diseases appearing in the differential diagnosis of brucellosis, among which are infections due to cross-reactive bacteria in brucellosis serology, like YO9 [43]. It is worthy to note that it is only since the early nineteen-nineties that YO9 has been regularly isolated in cattle in Europe [42], but also in other parts of the world including New Zealand [44]. Although YO9 infections do not seem to be associated with clinical signs in cattle, they induce what has been called "False Positive Serological Reactions" (FPSR) in brucellosis tests. Up to now, no single test is able to discriminate beyond any doubt a YO9 infection from brucellosis in cattle [42]. This causes a tremendous burden to trade of living animals and eradication programs. A very crucial question is to understand how and why YO9 was able to establish itself as an infective agent in cattle in the early nineteen-nineties. If the infec- tion becomes widely distributed and sustainable among cattle, we may face the same problems as observed in pigs. Essentially all brucellosis serological tests have so many limitations that the OIE questions the validity of brucellosis serological testing in this animal species [8].

Experimentally, a marine mammal Brucella spp. isolate from a Pacific harbor seal induced seroconversion and abortion in cattle [61]. Another important aspect of marine mammals brucellosis is the zoonotic potential of marine mammal brucellae [14, 66]. The clinical symptoms recorded during the accidental human laboratory infection were rather non-specific and the cause of such symptoms may not be easy to verify unless Brucella spp. infection is suspected [14]. Recently, marine mammal brucellae were identified in two patients from Peru with neurobrucellosis and intracerebral granulomas, which were the first reported cases on community-acquired human infections with marine mammal brucellae [66]. These last reported cases might raise new awareness and interest for such infections in humans.

New Brucella strains or species may emerge and existing Brucella spp. adapt to changing social, cultural, travel and agricultural environments. Hence, the global animal and human brucellosis picture will, in essence, always remain incomplete and regular updates are required.

\section{ACKNOWLEDGEMENTS}

Research at the laboratories of the authors is supported by the European Union (Research contracts FAIR CT 95-0134 and QLK2-CT199900014). We would like to thank our colleagues from the bovine and ovine/caprine brucellosis subgroups of the European "Brucellosis Task Force" established by the European Commission, Health \& Consumer Protection Directorate-General in accordance to the "White Paper on Food Safety" (DOC/00/1-COM/99/719).

This review is dedicated to our colleagues in our respective laboratories and in our national veterinary services for their expertise and commitment to the bovine and ovine/caprine brucellosis eradication programs. 


\section{REFERENCES}

[1] Abbas B., Agab H., A review of camel brucellosis, Prev. Vet. Med. 55 (2002) 47-56.

[2] Abou-Eisha A.M., Brucellosis in camels and its relation to public health, Assiut Vet. Med. J. 44 (2000) 54-64.

[3] Alton G.G., Jones L.M., Angus R.D., Verger J.M., Techniques for the Brucellosis Laboratory, First Edition, Institut National de la Recherche Agronomique, Paris, 1988.

[4] Almuneef M.A., Memish Z.A., Balkhy H.H., Alotaibi B., Algoda S., Abbas M., Alsubaie S., Importance of screening household members of acute brucellosis cases in endemic areas, Epidemiol. Infect. 132 (2004) 533-540.

[5] Andersen F.M., Pedersen K.B., Brucellosis. A case of natural infection of a cow with Brucella suis biotype 2, Dan. Vet. 78 (1995) 408

[6] Anonymous, Joint FAO/WHO Expert Committee on Brucellosis, 6th Rep., World Health Organization, Geneva, 1986.

[7] Anonymous, Joint FAO/WHO Expert Committee, The development of new improved brucellosis vaccine, WHO/EMC/ZDI/98.14, 1997.

[8] Anonymous, Manual of Standards for Diagnostic Tests and Vaccines, 12th ed., Office International des Epizooties, Paris, 2003.

[9] Ariza J., Pigrau C., Canas C., Marron A., Martinez F., Almirante B., Corredoira J.M., Casanova A., Fabregat J., Pahissa A., Current understanding and management of chronic hepatosplenic suppurative brucellosis, Clin. Infect. Dis. 32 (2001) 1024-1033.

[10] Awad R., Human brucellosis in the Gaza Strip, Palestine, East. Mediterr. Health J. 4 (1998) 225-233.

[11] Banai M., Control of small ruminant brucellosis by use of Brucella melitensis Rev. 1 vaccine: laboratory aspects and field observations, Vet. Microbiol. 90 (2002) 497-519.

[12] Baumgarten D., Brucellosis: a short review of the disease situation in Paraguay, Vet. Microbiol. 90 (2002) 63-69.

[13] Boschiroli M.L., Foulongne V., O'Callaghan D., Brucellosis: a worldwide zoonosis, Curr. Opin. Microbiol. 4 (2001) 58-64.

[14] Brew S.D., Perrett L.L., Stack J.A., MacMillan A.P., Staunton N.J., Human exposure to Brucella recovered from a sea mammal, Vet. Rec. 144 (1999) 483

[15] Bruce D., Note on the discovery of a microorganism in Malta Fever, Practitioner 39 (1887) 161.

[16] Capasso L., Bacteria in two-millennia-old cheese, and related epizoonoses in Roman populations, J. Infect. 45 (2002) 122-127.
[17] Carmichael L.E., Brucella canis, in: Nielsen K., Duncan J.R. (Eds.), Animal brucellosis, CRC Press, Boca Raton, 1990, pp. 335-350.

[18] Centers for Disease Control and Prevention, Case definitions for infectious conditions under public health surveillance, Morb. Mortal. Wkly. Rep. 46 (1997) 1-55.

[19] Centers for Disease Control and Prevention, Human Exposure to Brucella abortus Strain RB51 - Kansas, 1997, Morb. Mortal. Wkly. Rep. 47 (1998) 172-175.

[20] Centers for Disease Control and Prevention, Suspected Brucellosis case prompts investigation of possible bioterrorism-related activity-New Hampshire and Massachusetts, 1999, Morb. Mortal. Wkly. Rep. 49 (2000) 509512.

[21] Chomel B.B., DeBess E.E., Mangiamele D.M., Reilly K.F., Farver T.B., Sun R.K., Barrett L.R., Changing trends in the epidemiology of human brucellosis in California from 1973 to 1992: a shift toward foodborne transmission, J. Infect. Dis. 170 (1994) 1216-1223.

[22] Clavareau C., Wellemans V., Walravens K., Tryland M., Verger J.M., Grayon M., Cloeckaert A., Letesson J.J., Godfroid J., Phenotypic and molecular characterization of a Brucella strain isolated from a minke whale (Balaenoptera acutorostrata), Microbiology 144 (1998) 3267-3273.

[23] Cloeckaert A., Verger J.M., Grayon M., Paquet J.Y., Garin-Bastuji B., Foster G., Godfroid J., Classification of Brucella spp. isolated from marine mammals by DNA polymorphism at the omp2 locus, Microbes Infect. 3 (2001) 729-738.

[24] Cook D.R., Noble J.W., Isolation of Brucella suis from cattle, Aus.Vet. J. 61 (1984) 263264

[25] Cooper C.W., Risk factors in transmission of brucellosis from animals to humans in Saudi Arabia, Trans. R. Soc. Trop. Med. Hyg. 86 (1992) 206-209.

[26] Corbel M.J., Brucellosis: an overview, Emerg. Infect. Dis. 3 (1997) 213-221.

[27] Corbel M.J., Brinley-Morgan W.J., Genus Brucella Meyer and Shaw 1920, 173AL, in: Krieg N.R., Holt J.G. (Eds.), Bergey's manual of systematic bacteriology, Vol. 1, The Williams \& Wilkins Co., Baltimore, 1984, pp. 377 388.

[28] Crawford R.P., Huber J.D., Adams B.S., Epidemiology and surveillance, in: Nielsen K., Duncan J.R. (Eds.), Animal brucellosis, CRC Press, Boca Raton, 1990, pp. 131-151.

[29] Davis D.S., Brucellosis in wildlife, in: Nielsen K., Duncan J.R. (Eds.), Animal brucellosis, CRC Press, Boca Raton, 1990, pp. 321-334. 
[30] DelVecchio V.G., Kapatral V., Redkar R.J., Patra G., Mujer C., Los T., Ivanova N., Anderson I., Bhattacharyya A., Lykidis A., Reznik G., Jablonski L., Larsen N., D’Souza M., Bernal A., Mazur M., Goltsman E., Selkov E., Elzer P.H., Hagius S., O'Callaghan D., Letesson J.J., Haselkorn R., Kyrpides N., Overbeek R., The genome sequence of the facultative intracellular pathogen Brucella melitensis, Proc. Natl. Acad. Sci. USA 99 (2002) 443-448.

[31] Dobson A., Foufopoulos J., Emerging infectious pathogens of wildlife, Philos. Trans. R. Soc. Lond. B Biol. Sci. 356 (2001) 10011012.

[32] Ewalt D.R., Payeur J.B., Martin B.M. Cummings D.R., Miller G., Characteristics of a Brucella species from a bottlenose dolphin (Tursiops truncatus), J. Vet. Diagn. Invest. 6 (1994) 448-452.

[33] Ewalt D.R., Payeur J.P., Rhyan J.C., Geer P.L., Brucella suis biovar 1 in naturally infected cattle: a bacteriological, serological and histological study, J. Vet. Diagn. Invest. 9 (1997) 417-420.

[34] Forbes L.B., Isolates of Brucella suis biovar 4 from animals and humans in Canada, 19821990, Can. Vet. J. 32 (1991) 686-688.

[35] Fosgate G.T., Carpenter T.E., Chomel B.B., Case J.T., DeBess E.E., Reilly K.F., Timespace clustering of human brucellosis, California, 1973-1992, Emerg. Infect. Dis. 8 (2002) 672-678.

[36] Foster G., MacMillan A.P., Godfroid J. Howie F., Ross H.M., Cloeckaert A., Reid R.J., Brew S., Patterson I.A.P., A review of Brucella sp. infection of sea mammals with particular emphasis on isolates from Scotland, Vet. Microbiol. 90 (2002) 563-580.

[37] Garin-Bastuji B., Hars J., Calvez D., Thiébaud M., Artois M., Brucellosis of domestic pigs. Re-emergence of Brucella suis biovar 2 in France, Epidémiologie et Santé animale 38 (2000) 1-5 (in French)

[38] Gibbs E.P.J., The public health risks associated with wild and feral swine, Rev. Sci. Tech. Off. Int. Epizoot. 16 (1997) 594-598.

[39] Godfroid J., Brucellosis in wildlife, Rev. Sci. Tech. Off. Int. Epizoot. 21 (2002) 277-286.

[40] Godfroid J., Kasbohrer A., Brucellosis in the European Union and Norway at the turn of the twenty-first century, Vet. Microbiol. 90 (2002) 135-145.

[41] Godfroid J., Michel P., Uytterhaegen L., De Smedt C., Rasseneur F., Boelaert F., Saegerman C., Patigny X., Endemic brucellosis due to Brucella suis biotype 2 in the wild boar (Sus scrofa) in Belgium, Ann. Med. Vet. 138 (1994) 263-268 (in French).

[42] Godfroid J., Saegerman C., Wellemans V., Walravens K., Letesson J.J., Tibor A., Mc
Millan A., Spencer S., Sanna M., Bakker D., Pouillot R., Garin-Bastuji B., How to substantiate eradication of bovine brucellosis when aspecific serological reactions occur in the course of brucellosis testing, Vet. Microbiol. 90 (2002) 461-477.

[43] Gourdon F., Beytout J., Reynaud A., Romaszko J.P., Perre D., Theodore P., Soubelet H., Sirot J., Human and animal epidemic of Yersinia enterocolitica O:9, 1989-1997, Auvergne, France, Emerg. Infect. Dis. 5 (1999) 719-721.

[44] Hilbink F., Fenwick S.G., Thompson E.J., Kittelberger R., Penrose M., Ross G.P., Non specific seroreactions against Brucella abortus in ruminants in New Zealand and the presence of Yersinia enterocolitica O:9, N. Z. Vet. J. 43 (1995) 175-178.

[45] Jahans K.L., Foster G., Broughton E.S., The characterisation of Brucella strains isolated from marine mammals, Vet. Microbiol. 57 (1997) 373-382.

[46] Kaufmann A.F., Meltzer M.I., Schmid G.P., The economic impact of a bioterrorist attack: are prevention and postattack intervention programs justifiable? Emerg. Infect. Dis. 3 (1997) 83-94.

[47] Luna-Martinez J.E., Mejia-Teran C., Brucellosis in Mexico: current status and trends, Vet. Microbiol. 90 (2002) 19-30.

[48] Mantur B.G., Mangalgi S.S., Mulimani B., Brucella melitensis-a sexually transmissible agent, Lancet 347 (1996) 1763.

[49] Martin-Mazuelos E., Nogales M.C., Florez C., Gomez-Mateos J.M., Lozano F., Sanchez A., Outbreak of Brucella melitensis among microbiology laboratory workers, J. Clin. Microbiol. 32 (1994) 2035-2036.

[50] McDermott J.J., Arimi S.M., Brucellosis in sub-Saharan Africa: epidemiology, control and impact, Vet. Microbiol. 90 (2002) 111134.

[51] Memish Z.A., Balkhy H.H., Brucellosis and international travel, J. Travel. Med. 11 (2004) 49-55.

[52] Minas A., Minas M., Stournara A., Tselepidis S., The "effects" of Rev-1 vaccination of sheep and goats on human brucellosis in Greece, Prev. Vet. Med. 64 (2004) 41-47.

[53] Moreno E., Cloeckaert A., Moriyon I., Brucella evolution and taxonomy, Vet. Microbiol. 90 (2002) 209-227.

[54] Moriyon I., Grillo M.J., Monreal D., Gonzalez D., Marin C., Lopez-Goni I., Mainar-Jaime R.C., Moreno E., Blasco J.M., Rough vaccines in animal brucellosis: structural and genetic basis and present status, Vet. Res. 35 (2004) 1-38. 
[55] Navarro-Martinez A., Solera J., Corredoira J., Beato J.L., Martinez-Alfaro E., Atienzar M., Ariza J., Epididymoorchitis due to Brucella mellitensis: a retrospective study of 59 patients, Clin. Infect. Dis. 33 (2001) 2017-2022.

[56] Ohishi K., Zenitani R., Bando T., Goto Y., Uchida K., Maruyama T., Yamamoto S., Miyazaki N., Fujise Y., Pathological and serological evidence of Brucella-infection in baleen whales (Mysticeti) in the western North Pacific, Comp. Immunol. Microbiol. Infect. Dis. 26 (2003) 125-136.

[57] Paton N.I., Tee N., Vu C.H., Teo T., Visceral abscesses due to Brucella suis infection in a retired pig farmer, Clin. Infect. Dis. 32 (2001) 129-130.

[58] Paulsen I.T., Seshadri R., Nelson K.E., Eisen J.A., Heidelberg J.F., Read T.D., Dodson R.J., Umayam L., Brinkac L.M., Beanan M.J., Daugherty S.C., Deboy R.T., Durkin A.S., Kolonay J.F., Madupu R., Nelson W.C., Ayodeji B., Kraul M., Shetty J., Malek J., Van Aken S.E., Riedmuller S., Tettelin H., Gill S.R., White O., Salzberg S.L., Hoover D.L., Lindler L.E., Halling S.M., Boyle S.M., Fraser C.M., The Brucella suis genome reveals fundamental similarities between animal and plant pathogens and symbionts, Proc. Natl. Acad. Sci. USA 99 (2002) 1314813153.

[59] Refai M., Incidence and control of brucellosis in the Near East region, Vet. Microbiol. 90 (2002) 81-110.

[60] Rhyan J.C., Brucellosis in terrestrial wildlife and marine mammals, in: Brown K., Bolin C. (Eds.), Emerging diseases of animals, ASM Press, Washington, 2000, pp. 161-184.

[61] Rhyan J.C., Gidlewski T., Ewalt D.R., Hennager S.G., Lambourne D.M., Olsen S.C., Seroconversion and abortion in cattle experimentally infected with Brucella sp. isolated from a Pacific harbor seal (Phoca vitulina richardsi), J. Vet. Diagn. Invest. 13 (2001) 379-382.

[62] Robson J.M., Harrison M.W., Wood R.N., Tilse M.H., McKay A.B., Brodribb T.R., Brucellosis: re-emergence and changing epidemiology in Queensland, Med. J. Aust. 159 (1993) 153-158.

[63] Ross H.M., Foster G., Reid R.J., Jahans K.L., MacMillan A.P., Brucella species infection in sea-mammals, Vet. Rec. 134 (1994) 359.

[64] Samartino L.E., Brucellosis in Argentina, Vet. Microbiol. 90 (2002) 71-80.

[65] Schurig G.G., Sriranganathan N., Corbel M.J., Brucellosis vaccines: past, present and future, Vet. Microbiol. 90 (2002) 479-496.

[66] Sohn A.H., Probert W.S., Glaser C.A., Gupta N., Bollen A.W., Wong J.D., Grace E.M., Mc Donald W.C., Human neurobrucellosis with intracerebral granuloma caused by a marine mammal Brucella spp., Emerg. Infect. Dis. 9 (2003) 485-488.

[67] Teyssou R., Morvan J., Leleu J.P., Roumegou P., Goullin B., Carteron B., A case of brucellosis in man due to Brucella suis biovar 2, Med. Mal. Infect. 19 (1989) 160-161 (in French).

[68] Thakur S.D., Kumar R., Thapliyal D.C., Human brucellosis: review of an under-diagnosed animal transmitted disease, J. Commun. Dis. 34 (2002) 287-301.

[69] Tryland M., Kleivane L., Alfredson A., Kjeld M., Arnason A., Godfroid J., Evidence of Brucella spp. in marine mammals in the North Atlantic Ocean and Barents Sea, Vet. Rec. 144 (1999) 588-592.

[70] van der Leek M.L., Becker H.N., Humphrey P., Adams C.L., Belden R.C., Frankenberger W.B., Nicoletti P.L., Prevalence of Brucella sp. antibodies in feral swine in Florida, J. Wildl. Dis. 29 (1993) 410-415.

[71] Verger J.M., Grimont F., Grimont P.A.D., Grayon M., Brucella, a monospecific genus as shown by deoxyribonucleic acid hybridization, Int. J. Syst. Bacteriol. 35 (1985) 292 295.

[72] Verger J.M., Garin-Bastuji B., Grayon M., Mahe A.M., Bovine brucellosis caused by Brucella melitensis in France, Ann. Rech. Vet. 20 (1989) 93-102.

[73] Wallach J.C., Samartino L.E., Efron A., Baldi P.C., Human infection by Brucella melitensis: an outbreak attributed to contact with infected goats, FEMS Immunol. Med. Microbiol. 19 (1997) 315-321.

[74] Wise R.I., Brucellosis in the United States, Past, present, and future, JAMA 244 (1980) 2318-2322.

[75] Wobester G.A., Investigation and management of disease in wild animals, Plenum Press, New York, 1994.

[76] Young E.J., An overview of human brucellosis, Clin. Infect. Dis. 21(1995) 283-289.

[77] Young E.J., Corbel M.J., Brucellosis: clinical and laboratory aspects, CRC Press, Boca Raton, 1989.

[78] Zammit T., A preliminary note on the examination of the blood of goats suffering from Mediterranean fever, reports of the Commisssion on Mediterranean Fever, Part III, Harrison and Sons, London, 1905, p. 83.

[79] Zygmont S.M., Nettles V.F., Shotts E.B. Jr, Carmen W.A., Blackburn B.O., Brucellosis in wild swine: a serologic and bacteriologic survey in the southeastern United States and Hawaii, J. Am. Vet. Med. Assoc. 181 (1982) 1285-1287. 